\title{
NARCISSISTIC PERSONALITY DISORDER OVER TIME- FROM NARCISSUS TO SELFIES
}

\section{Laura Mariano da Rocha, M.D., Ph.D.. Hospital Nossa Senhora da Conceição, Porto Alegre, Brazil}

This paper aims to bring a review of narcissism through the ages, from the first use of the term, through several authors from Freud, Andre Green, Otto Kernberg, Rosenfeld and Kohut until we reach the 21st century, with their social networks and apology to seem in detriment of feeling and being. The influence of contemporaneity with ts technologies and social networks influencing behavior and increased narcissism among people is also contemplated.

The word narcissus comes from the Greek Narkes which means numbness. It refers to Narcissus, and represents vanity. The notion of narcissism would have been formed in two moments:Havelock Ellis made the first allusion to it in 1898 to characterize a self-centered form of love; for him, narcissism is an extreme form of self-erotic behavior, where the other is not present in the process of arousal and discharge of sexual energy. A year later, Paul Nacke would have coined the word narcissism.

According to Kernberg, narcissism is a way of regulating selfesteem. Normal narcissism implies a healthy level of investment in self-esteem, the interests of the individual and their preservation in order to achieve their goals.

Psychoanalysts who follow Freud in his conception of primary narcissism think that there is a phase in early life when the child does not yet know the object: it is for them a normal phase of child development. Winnicott is one of the psychoanalysts who adheres to the idea that primary identification is present early in life,although not as primary narcissism.

Psychoanalysts who follow M. Klein consider that from the beginning of life an object relation has been established; for them, there is no primary narcissistic phase in the child but only "narcissistic phases."

For Rosenfeld, narcissism is based on the omnipotence and idealization of the self obtained through introjective and projective identification with the idealized object. This identification led to denying the difference and the boundary between self and object. In a position very close to Rosenfeld, $H$. Segal considers that the concept of life and death drive may help to solve the problem of Freud's hypothesis of primary narcissism.

Green talks about a double attack on self-libido and on object investing, where positive narcissism favors self-libido over objects and negative narcissism disinvents self-libido without passing it on to objects. In this way, it seems that the self is disinterested in both itself and the object, wishing only to disappear. According to Kernberg (1975), there are three types of narcissism: the adult normal, the child normal and the pathological. At the origin of narcissistic pathology is a failure or excessive parental gratification that causes the subject to feel anger and / or envy at the primary object objects, leading him to his liberating triumph. Rosenfeld distinguished narcissistic patients with thin and thick skin. The thick-skinned ones would be characterized by striking self-confidence and grandeur. Those with thin skin are extremely sensitive to any kind of criticism or threaten their self-esteem.
To Kohut "The narcissistic organization of personality is a natural attempt to cope with the irregular maturative situations that inevitably occur in child development, since good maternal care is always insufficient.

The term "narcissism" has served as an adjective for the culture in which we are living in the twentieth and twenty-first centuries as synonym for emotional superficiality, arrogance, affective distancing, hedonism.

Today's modernity is also an appeal to speed, constant production, and continued consumerism. The goals to be pursued are fragile and change very often.

In addition, the contemporaneity is marked by the lack of limits. There are no more limits to inclusive satisfaction. We are in the culture of "carpe diem" (to reap the day or enjoy the moment), of immediacy, in an intense preoccupation with the length of things. Immediate pleasure is what counts, aided by technology that makes it easy to do everything.

In today's world, with countless possibilities, emptiness would be revealed by excess, lack of lack. In narcissism, libido is not directed at the object, which makes desire not problematized. A narcissistic relationship is then established with desire where there is only room for one and the other to be excluded.

Thus, all that desired in narcissistic pathologies is translated as necessity. Hence the search for immediate satisfaction, of a more bodily-sensational order without waiting, which is what leads to psychic elaboration.

For Larsch, contemporary narcissism would be a defense against the tensions and anxieties of modern life.

Ultimately, the narcissistic personality and fruit of the persistence of childhood narcissism in adulthood and contemporary culture is immersed in new modes of socialization and modes of experience organization, so narcissism emerges in this scenario as a means of understanding the psychological impact of recent social changes.

Nowadays, we can see Narcissus's myth in technologies, especially with the use of social networks (like facebook, Instagram, twitter), the "selfies", where the intention is not just the constant exposure, but also a search for the compliment and look of the other to be recognized, loved, through a "like".

Thus, more and more relationships become superficial, that is, when they are really in contact with each other, the individual barely exposes what he wants, feels, thinks, because he is so focused on his selfie, for himself, as a Brazilian composer said "Narcissus hates everything that is not a mirror", and "selfie" is nothing more than a form of mirror!

Thus, one does not even recognize one another in the eyes of another, no longer knows what one is looking for and as in the myth, one can succumb to one's own admiration. In addition to the photos of yourself, the moments lived are also very shared, but really living them is necessary! 